\title{
Demonstration of Functional Coupling between Dopamine Synthesis and Its Packaging into Synaptic Vesicles
}

\author{
Rong Chen ${ }^{a}$ Jianning Wei ${ }^{b}$ Stephen C. Fowler ${ }^{a}$ Jang-Yen Wu ${ }^{c}$ \\ a Department of Pharmacology and Toxicology and ${ }^{\mathrm{b}}$ Molecular Biosciences, University of Kansas, Lawrence, Kans.; \\ 'Department of Biomedical Science, Florida Atlantic University, Boca Raton, Fla., USA
}

\section{Key Words}

Dopamine synthesis - Membrane-associated tyrosine hydroxylase $\cdot$ Synaptic vesicles $\cdot$ Protein phosphorylation. Dopamine packaging

\begin{abstract}
We have previously shown that the membrane-associated form of the GABA-synthesizing enzyme, glutamate decarboxylase $65\left(G A D_{65}\right)$, is activated by synaptic vesicle proton gradient-mediated protein phosphorylation. We now report that the rate-limiting enzyme in dopamine (DA) biosynthesis, tyrosine hydroxylase (TH), is regulated similarly to $\mathrm{GAD}_{65}$. The membrane-associated form of $\mathrm{TH}$ (MTH) was activated by conditions favoring protein phosphorylation (e.g. ATP) and was inhibited by phosphatase (e.g. calf intestine phosphatase). Furthermore, the ATP-mediated activation of MTH was abolished by conditions that disrupted the proton gradient of synaptic vesicles, e.g. the presence of carbonyl cyanide $m$-chorophenylhydrazone, gramicidin, or the V-type ATPase inhibitor (bafilomycin), but not the P-type ATPase inhibitor (vanadate). Moreover, DA newly synthesized from tyrosine by MTH and membrane-associated aromatic amino acid decarboxylase was taken up
\end{abstract}

\section{KARGER}

Fax +41613061234

E-Mailkarger@karger.ch www. karger.com

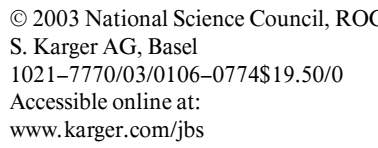

preferentially rather than pre-existing DA. Therefore, the previously proposed model showing close coupling between GABA synthesis and GABA packaging into synaptic vesicles by vesicular GABA transporters is also applicable to the DA system. Hence, it is concluded that there is a general coupling mechanism between neurotransmitter synthesis and packaging of transmitter into synaptic vesicles.

Copyright $\odot 2003$ National Science Council, ROC and S. Karger AG, Basel

\section{Introduction}

Tyrosine hydroxylase (TH; EC 1.14.16.2) is the initial enzyme in the biosynthesis of the catecholamines including dopamine (DA), norepinephrine, and epinephrine. TH catalyzes the hydroxylation of $L$-tyrosine to form 3,4dihydroxylphenylalanine ( $L$-Dopa). It is a tetrahydropteridine $\left(\mathrm{BH}_{4}\right)$-dependent, iron-containing monooxygenase. $L$-Dopa is further decarboxylated by aromatic $L$-amino acid decarboxylase (AADC; EC 4.1.1.28) to form DA. In the central nervous system, $\mathrm{TH}$ has been shown to exist in two distinct forms, namely, soluble TH (STH) and membrane-bound TH (MTH) [13, 14]. Alterations in the level of DA induced by $\mathrm{TH}$ or AADC in the central nervous
Dr. Jang-Yen Wu

Charles E. Schmidt Senior Fellow, Biomedical Science Program

Florida Atlantic University, 777 Glades Road

Boca Raton, FL 33431 (USA)

Te. +1 561297 0167, Fax +1 561297 0174, E-Mail jwu@fau.edu 
system have been implicated in neurodegenerative diseases, including Parkinson's disease [19], Huntington's disease [1], and schizophrenia [10].

Like other neurotransmitter-synthesizing enzymes, such as $L$-glutamate decarboxylase (GAD) [2, 10], choline acetyltransferase, cysteine sulfonic acid decarboxylase [17], phosphorylation of TH plays an important role in the regulation of TH activity and DA biosynthesis. Accumulating evidence has shown that various protein kinases catalyze the phosphorylation of $\mathrm{TH}$ at multiple serine sites of the enzyme, e.g. $\mathrm{Ser}^{8}, \mathrm{Ser}^{19}, \mathrm{Ser}^{31}$, and $\mathrm{Ser}^{40}$ sites. For instance, a proline-directed protein kinase isolated from PC 12 cells has been shown to phosphorylate $\mathrm{TH}$ at the $\mathrm{Ser}^{8}$ residue [18]. In rat pheochromocytoma cells and brain synaptosomes, $\mathrm{Ca}^{2+} /$ calmodulin-dependent protein kinase II (CaMKII) has been reported to phosphorylate $\mathrm{TH}$ at $\operatorname{Ser}^{19}[3,9]$. Two microtubule-associated extracellular signal-regulated kinases, ERK1 and ERK2, appear to phosphorylate $\mathrm{TH}$ at $\mathrm{Ser}^{31}$ [8]. In addition, cyclic AMP (cAMP)-dependent protein kinase (PKA) phosphorylates $\mathrm{TH}$ at $\operatorname{Ser}^{40}$ [9]. In contrast to the large number of protein kinases involved in the phosphorylation of $\mathrm{TH}$, dephosphorylation of $\mathrm{TH}$ appears to be mediated by a single protein phosphatase identified as protein phosphatase $2 \mathrm{~A}$ [7].

Despite extensive studies on STH, little is known about the regulation of brain MTH. We have previously shown that the membrane-associated form of the $\gamma$-aminobutyric acid (GABA) synthesizing enzyme, $L$-glutamic acid decarboxylase $\left(\mathrm{GAD}_{65}\right)$, is activated by synaptic vesicle proton gradient-mediated protein phosphorylation [10]. In this communication, we report that MTH is regulated in a similar manner by a vesicular proton gradient and protein phosphorylation.

In the GABAergic system, we have demonstrated that vesicular GABA transporters (VGAT) preferentially transport GABA newly synthesized from glutamate rather than pre-existing GABA, and the presence of GAD inhibitor decreases GAD activity as well as VGAT activity [12]. Further investigation reveals that VGAT forms a protein complex with $\mathrm{GAD}_{65}$ on the synaptic vesicles, which ensures an efficient coupling between GABA synthesis and packaging into the synaptic vesicles [12]. Here, we report a coupling mechanism in the DA system between DA synthesis and its packaging into synaptic vesicles similar to that demonstrated for the GABAergic system [12].

Dopamine Synthesis and Transport

\section{Materials and Methods}

\section{Materials}

Fresh porcine brains were obtained from a local slaughterhouse. Ascorbic acid, adenosine diphosphate (ADP), adenosine monophosphate (AMP), adenosine triphosphate (ATP), bafilomycin A1, calf intestinal phosphatase (CIP), carbonyl cyanide $m$-chorophenylhydrazone (CCCP), catalase, cAMP, gramicidin, mercaptoethanol, phospho(enol)pyruvate, pyridoxal 5'-phosphate, pyruvate kinase, sodium fluoride $(\mathrm{NaF})$, sodium orthovanadate, and $\mathrm{BH}_{4}$ were purchased from Sigma (St. Louis, Mo.). $L-\left[3,5-{ }^{3} \mathrm{H}\right]$ tyrosine, $\left[{ }^{14} \mathrm{C}(\mathrm{U})\right]$ tyrosine, and $\left[3,5-{ }^{3} \mathrm{H}\right] \mathrm{DA}$ were purchased from Amersham Biosciences (Piscataway, N.J.).

\section{Preparation of Synaptosomes}

Unless otherwise specified, all procedures were carried out at $4{ }^{\circ} \mathrm{C}$. Substantia nigra, striatum, frontal cortex, and locus ceruleus were dissected from fresh porcine brains. Crude synaptosomes were prepared as described before [10]. Briefly, the dissected tissues were homogenized in $0.32 \mathrm{M}$ sucrose (w/v, $15 \mathrm{~g} / 100 \mathrm{ml}$ ), and the homogenate was centrifuged at $1,000 \mathrm{~g}$ for $10 \mathrm{~min}$ to remove nuclei and debris (P1). The resulting supernatant liquid (S1) was collected and further centrifuged at $12,000 \mathrm{~g}$ for $1 \mathrm{~h}$. The pellet thus obtained (P2) is referred to as the crude synaptosomes. They were divided into aliquots and stored at $-70^{\circ} \mathrm{C}$ until used.

\section{Preparation of STH and MTH}

The frozen synaptosomal samples were thawed, suspended, and sonicated in the standard TH buffer containing $50 \mathrm{~m} M$ Tris-maleate (pH 6.8), $2 \mathrm{~m} M$ $\beta$-mercaptoethanol, $50 \mathrm{~m} M$ sodium fluoride, and $0.1 \mathrm{~m} M$ EDTA. The homogenate was centrifuged at $100,000 \mathrm{~g}$ for $1 \mathrm{~h}$. The resulting supernatant and pellet were used as the sources of STH and MTH, respectively. The pellet was resuspended in the standard TH buffer. Both the supernatant and resuspension samples were dialyzed extensively against dialysis buffer containing $50 \mathrm{~m} M$ Tris-maleate ( $\mathrm{pH}$ 6.8), $50 \mathrm{~m} M$ sodium fluoride, $0.1 \mathrm{~m} M$ EDTA, and $0.001 \%$ leupeptin.

\section{Treatment with CIP}

Treatment of STH and MTH samples with the CIP was conducted as described previously [10] with some modifications. The STH sample was applied to a CIP-conjugated agarose (714 units $/ \mathrm{ml}$ ) column, which had been pre-equilibrated with $50 \mathrm{~m} M$ Tris-citrate $\left(\mathrm{pH} \mathrm{7.4)}\right.$ at $30^{\circ} \mathrm{C}$. After application of the sample, the column was stopped for $10 \mathrm{~min}$ to allow the STH sample to react with CIP. The column was then washed with five column volumes of $25 \mathrm{~m} M$ Triscitrate buffer ( $\mathrm{pH}$ 7.4), and the eluate collected was assayed for $\mathrm{TH}$ activity. The MTH sample was incubated with $10 \mu \mathrm{l}$ free CIP $(1,100$ units) at $30^{\circ} \mathrm{C}$ for $20 \mathrm{~min}$. The reaction mixture was then centrifuged at $100,000 \mathrm{~g}$ for $1 \mathrm{~h}$ to remove CIP. The pellet was resuspended in the standard TH buffer and assayed for TH activity.

\section{Determination of TH Activity}

The activity of $\mathrm{TH}$ was measured based on the release of tritiated water as described by Reinhard et al. [15]. Briefly, the reaction mixture consisted of $150 \mathrm{~m} M$ Tris-maleate (pH 6.8), $500 \mu M \mathrm{BH}_{4}$, $100 \mu M$ magnesium sulfate, $3,000 \mathrm{U}$ of catalase, $5 \mathrm{~m} M$ ascorbic acid, $1.0 \mu \mathrm{Ci} L-\left[3,5-{ }^{3} \mathrm{H}\right]$ tyrosine, and $100 \mu \mathrm{l}$ sample in a final volume of $250 \mu \mathrm{l}$. The reaction was carried out at room temperature for $20 \mathrm{~min}$ and was terminated by addition of $1 \mathrm{ml}$ of $7.5 \%(\mathrm{w} / \mathrm{v})$ charcoal slurry

J Biomed Sci 2003;10:774-781 
containing $1 \mathrm{MHCl}$. The samples were well mixed with charcoal and left at room temperature for $30 \mathrm{~min}$, followed by brief centrifugation at $3,000 \mathrm{~g}$ for $5 \mathrm{~min}$. An aliquot of $400 \mu \mathrm{l}$ of supernatant was removed for determination of radioactivity using a liquid scintillation counter. Bafilomycin A1, CCCP, and gramicidin were dissolved in ethanol in stock solutions; the ethanol concentration did not exceed $1 \%$ of the incubation volume in the assay mixture. The controls containing the same amount of ethanol were also included for each condition.

\section{Preparation of Synaptic Vesicles}

Briefly, crude synaptosomes obtained as described above were resuspended and homogenized in 10 times the volume of cold distilled deionized water for $1 \mathrm{~min}$. Osmolarity was restored by addition of potassium chloride to a final concentration of $130 \mathrm{~m} M$. Samples were centrifuged for $20 \mathrm{~min}$ at $20,000 \mathrm{~g}$ to remove lysed synaptosomal membranes. The collected supernatant was then centrifuged for $1 \mathrm{~h}$ at $250,000 \mathrm{~g}$. The resulting pellets containing synaptic vesicles were suspended in $\mathrm{KH}$ buffer $(90 \mathrm{~m} M \mathrm{KCl}, 50 \mathrm{~m} M$ HEPES, $\mathrm{pH}$ 7.4, at $30^{\circ} \mathrm{C}$ ), and referred to as crude synaptic vesicles.

Vesicular Uptake Assay with $\left[{ }^{14} C\right] D A$ Newly Synthesized from

$\left[{ }^{14} \mathrm{C}\right]$ Tyrosine and the Pre-Existing $\left[{ }^{3} \mathrm{H}\right] \mathrm{DA}$

The uptake assay was conducted as described by Floor et al. [5] with modifications. Briefly, synaptic vesicles $(1 \mathrm{mg}$ of protein $/ \mathrm{ml})$ were preincubated in $\mathrm{KH}$ buffer containing $250 \mu \mathrm{g} / \mathrm{ml}$ pyruvate kinase at $30.0 \pm 0.01^{\circ} \mathrm{C}$ for $2 \mathrm{~min}$ in borosilicate glass test tubes. Uptake was initiated by adding the following compounds in $\mathrm{KH}$ buffer to final concentrations of $10 \mu M\left[{ }^{14} \mathrm{C}(\mathrm{U})\right]$ tyrosine, $500 \mu M$ $\mathrm{BH}_{4}, 100 \mu M$ magnesium sulfate, $3,000 \mathrm{U}$ of catalase, $5 \mathrm{~m} M$ ascorbic acid, $0.2 \mathrm{~m} M$ pyridoxal 5'-phosphate at pH 7.2, $17 \mathrm{n} M L$-[3,5$\left.{ }^{3} \mathrm{H}\right] \mathrm{DA}, 2 \mathrm{~m} M$ ATP, $4.4 \mathrm{~m} M \mathrm{MgSO}_{4}, 12 \mathrm{~m} M$ phospho(enol)pyruvate, $1 \mathrm{mg} / \mathrm{ml}$ vesicle protein, and $100 \mu \mathrm{g} / \mathrm{ml}$ pyruvate kinase. For $\left[{ }^{3} \mathrm{H}\right] \mathrm{DA}$ and $\left[{ }^{14} \mathrm{C}\right] \mathrm{DA}$ uptake measurements, a $50-\mu \mathrm{l}$ aliquot of the reaction mixture at different time intervals was applied to a nitrocellulose filter $(0.45 \mu \mathrm{m})$ and free $\left[{ }^{14} \mathrm{C}\right]$ tyrosine, $\left[{ }^{3} \mathrm{H}\right] \mathrm{DA}$ and $\left[{ }^{14} \mathrm{C}\right] \mathrm{DA}$ were removed by vacuum-assisted filtration. The filter was washed twice with $5 \mathrm{ml}$ of ice-cold $\mathrm{KH}$ buffer within $\sim 5 \mathrm{~s}$, and promptly removed. Filters were dried and radioactivity trapped in filter was counted using a liquid scintillation counter. Nonspecific uptake of $\left[{ }^{3} \mathrm{H}\right] \mathrm{DA}$ was measured in the presence of CCCP. Since dual isotopes were applied, two separate channels were used for counting ${ }^{14} \mathrm{C}$ and ${ }^{3} \mathrm{H}$ activity.

Separation of DA from Tyrosine by an Anion Exchange Column

To verify that the content taken up into synaptic vesicles was $\left[{ }^{14} \mathrm{C}\right] \mathrm{DA}$ instead of $\left[{ }^{14} \mathrm{C}\right]$ tyrosine or $\left[{ }^{3} \mathrm{H}\right] \mathrm{DA}$, an anion-exchange resin column was employed (Bio-Rad AG1X8 200-400 mesh chloride form). The separation of standard tyrosine and DA was carried out as described by Shibuya et al. [16] with modifications. Briefly, standard tyrosine $(45,000 \mathrm{dpm})$ or DA $(15,000 \mathrm{dpm})$ in $500 \mu \mathrm{l}$ of the KH buffer was applied to the column, followed by washing with water and then $80 \mathrm{~m} M \mathrm{HCl}$. Tyrosine was not retained by the resin and flowed through while DA was eluted out after application of $\mathrm{HCl}$.

To establish the identity of the contents transported into synaptic vesicles, aliquots of the extract from the synaptic vesicles were applied to the column as described [12]. The column was first washed with $\mathrm{H}_{2} \mathrm{O}$ until no radioactivity was detected, followed by elution with $80 \mathrm{mM} \mathrm{HCl}$. Eluates were collected at $1.5 \mathrm{ml}$ per fraction, and the radioactivity was counted in a scintillation counter. Two channels were used for counting ${ }^{3} \mathrm{H}$ and ${ }^{14} \mathrm{C}$ isotopes separately.

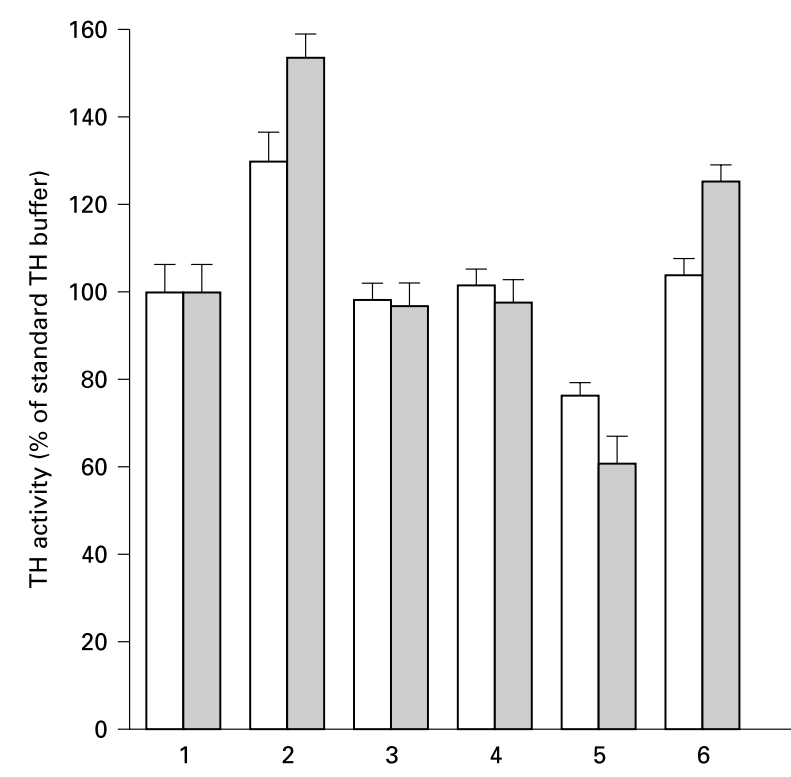

Fig. 1. Effect of ATP and protein phosphatase inhibitors on $\mathrm{TH}$ activity. The STH and MTH samples were prepared as described under 'Materials and Methods'. The TH samples were incubated at $37^{\circ} \mathrm{C}$ for $30 \mathrm{~min}$ under the following conditions. Lane 1: standard TH buffer; lane 2: standard TH buffer + $5 \mathrm{mM}$ ATP; lane 3: standard TH buffer + $5 \mathrm{~m} M$ ADP; lane 4: standard TH buffer + $5 \mathrm{~m} M$ AMP; lane 5: standard TH buffer $+2 \mathrm{~m} M$ EGTA; lane 6: standard TH buffer + phosphatase inhibitors $(0.2 \mathrm{~m} M$ vanadate, $2 \mathrm{~m} M$ sodium fluoride and $0.2 \mathrm{~m} M$ sodium pyrophosphate). Values represent means and error bars represent the standard deviation of three determinations.

\section{Results}

\section{Effects of ATP and Phosphatase Inhibitors on TH Activity}

Both MTH and STH were activated under the conditions favoring protein phosphorylation, e.g. in the presence of ATP or protein phosphatase inhibitors, as indicated in figure 1 . The activity of STH and MTH was increased by ATP to 29 and 53\%, respectively (fig. 1, lane 2). ADP and AMP at the same concentration as ATP had no effect on the activity of both forms of TH (fig. 1, lanes 3 and 4). The presence of the divalent cation chelator, 2 $\mathrm{m} M$ EGTA, significantly attenuated both MTH and STH activity (fig. 1, lane 5), suggesting a possible role of calcium in TH regulation. Other phosphatase inhibitors, e.g. $0.2 \mathrm{~m} M$ vanadate, $2 \mathrm{~m} M$ sodium fluoride, and $0.2 \mathrm{~m} M$ sodium pyrophosphate significantly inhibited the MTH 


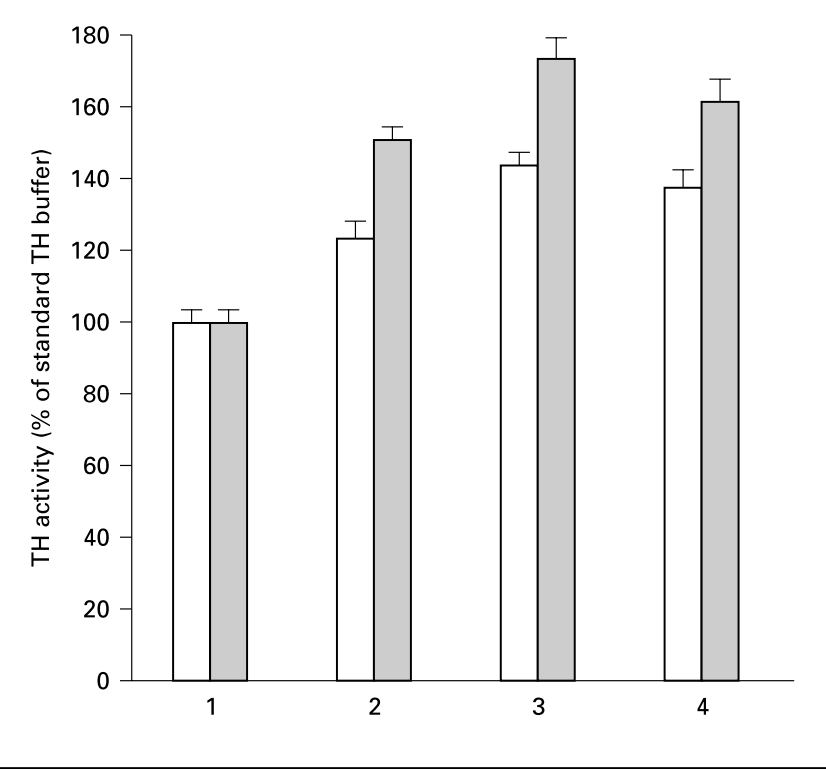

Fig. 2. Effects of protein kinase activators on TH activity. The STH and MTH samples were incubated under the following conditions. Lane 1: standard TH buffer only; lane 2: TH buffer + ATP $(5 \mathrm{mM})$; lane 3: TH buffer + ATP $(5 \mathrm{~m} M)+$ cAMP $(1 \mathrm{~m} M)$; lane 4: TH buffer $+\operatorname{ATP}(5 \mathrm{~m} M)+\mathrm{CaCl}_{2}(1 \mathrm{~m} M)$. Values represent means and error bars represent the standard deviation of three determinations.

activity, while STH activity was slightly increased (fig. 1, lane 6).

\section{Effects of Protein Kinase Activators on TH Activity}

As shown in figure 2, PKA activator, cAMP, greatly enhanced the ATP activation of both forms of TH (lane 3). However, $\mathrm{Ca}^{2+}$, an activator for both PKC and CaMKII, only slightly stimulated the ATP activation of both forms of TH (fig. 2, lane 4).

\section{Effects of Phosphatase Treatment on TH Activity}

The treatment of nonspecific phosphatase, CIP, reduced $\mathrm{TH}$ activity as indicated in figure 3 . The activity of STH and MTH was reduced by CIP to 18 and $22 \%$, respectively (lane 3 ). The activity of CIP-treated STH and MTH was increased substantially by 40 and $78 \%$, respectively, in the presence of $5 \mathrm{mM}$ ATP (lane 4).

Dependence of ATP Activation of MTH on the Proton Gradient Across the Synaptic Vesicles

When the proton gradient across synaptic vesicles was disrupted by the protonophore uncoupler, CCCP

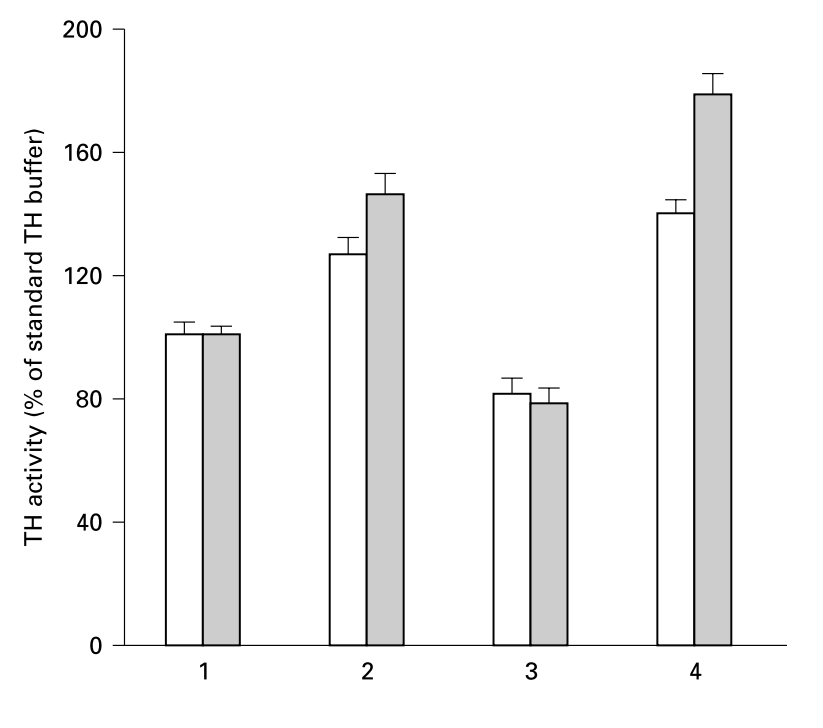

Fig. 3. Effects of phosphatase on TH activity. Both STH and MTH samples were treated with CIP) as described in 'Materials and Methods'. Lane 1: TH buffer as control; lane 2: TH buffer + $5 \mathrm{~m} M$ ATP; lane 3: treatment with CIP; lane 4: same as lane 3, followed by addition of $5 \mathrm{~m} M$ ATP. Data are expressed as the mean \pm the standard deviation. Values represent means and error bars represent the standard deviation of three determinations.
$(100 \mu M)$, or ionophore, gramacidin $(10 \mu M)$, the ATP activation of MTH was almost completely abolished, as shown in figure 4 (lanes 4 and 6). In addition, bafilomycin A1, a specific V-type ATPase inhibitor, at the concentration of $6 \mu M$ also abolished ATP activation of MTH (lane 8). However, vanadate, a P-type ATPase inhibitor, had no effect on ATP activation of MTH (lane 10).

\section{Preferential Uptake of the Newly Synthesized \\ Dopamine from Tyrosine Rather than from the \\ Pre-Existing Dopamine in Cytosolic Pools}

To illustrate that DA vesicles preferentially take up newly synthesized DA, dual radioactive-labeled $\left[{ }^{3} \mathrm{H}\right] \mathrm{DA}$ and $\left[{ }^{14} \mathrm{C}\right]$ tyrosine were used as pre-existing DA pool and newly synthesized DA, respectively. $10 \mu M(46 \mu \mathrm{Ci})$ of $\mathrm{U}-\left[{ }^{14} \mathrm{C}\right]$ tyrosine and $17 \mathrm{n} M(0.5 \mu \mathrm{Ci})$ of $\left[{ }^{3} \mathrm{H}\right] \mathrm{DA}$ were included in $250 \mu \mathrm{l}$ of uptake reaction mixture. Based on the $\mathrm{TH}$ activity assays under the same conditions, only $0.16 \%$ of tyrosine was converted to DA. This would give a concentration of newly synthesized $\left[{ }^{14} \mathrm{C}\right] \mathrm{DA}$ in the uptake mixture around $17 \mathrm{n} M$, which is the concentration used for the pre-existing $\left[{ }^{3} \mathrm{H}\right] \mathrm{DA}$. As indicated in figure 5, the 
Fig. 4. Dependence of ATP activation of MTH on the proton gradient across synaptic vesicles. Effects of various proton gradient uncouplers or inhibitors on $\mathrm{TH}$ activity alone or on ATP activation of TH were studied as described in 'Materials and Methods'. $\mathrm{CCCP}$ and gramicidin were dissolved in ethanol in stock solution. The controls contained ethanol in concentrations not to exceed $1 \%$ of the incubation volume. Lane 1 : control; lane 2: ATP alone (5 $\mathrm{mM})$; lane 3: CCCP alone $(100 \mu M)$; lane 4: ATP $(5 \mathrm{mM})$ + CCCP $(100 \mu M)$; lane 5: gramicidin alone $(10 \mu M)$; lane 6: ATP $(5 \mathrm{mM})+$ gramicidin $(10 \mu M)$; lane 7: bafilomycin alone $(6 \mu M)$; lane 8: ATP $(5 \mathrm{mM})+$ bafilomycin $(6 \mu M)$; lane 9: vanadate alone $(200 \mu M)$; lane 10: ATP $(5 \mathrm{~m} M)+$ vanadate $(200 \mu M)$. Values represent means and error bars represent the standard deviation of three determinations.

Fig. 5. A comparison of DA uptake from newly synthesized DA versus pre-existing DA. $\left[{ }^{14} \mathrm{C}\right]$ tyrosine was used to generate newly synthesized $\left[{ }^{14} \mathrm{C}\right] \mathrm{DA}$ in the uptake assay system, while $\left[{ }^{3} \mathrm{H}\right] \mathrm{DA}$ was included as preexisting DA in uptake experiments. Uptake of DA is expressed as picomoles/milligram protein. DA uptake in the presence of CCCP was used as nonspecific uptake and was subtracted from total uptake. Values represent means and error bars represent the standard deviation of three determinations.
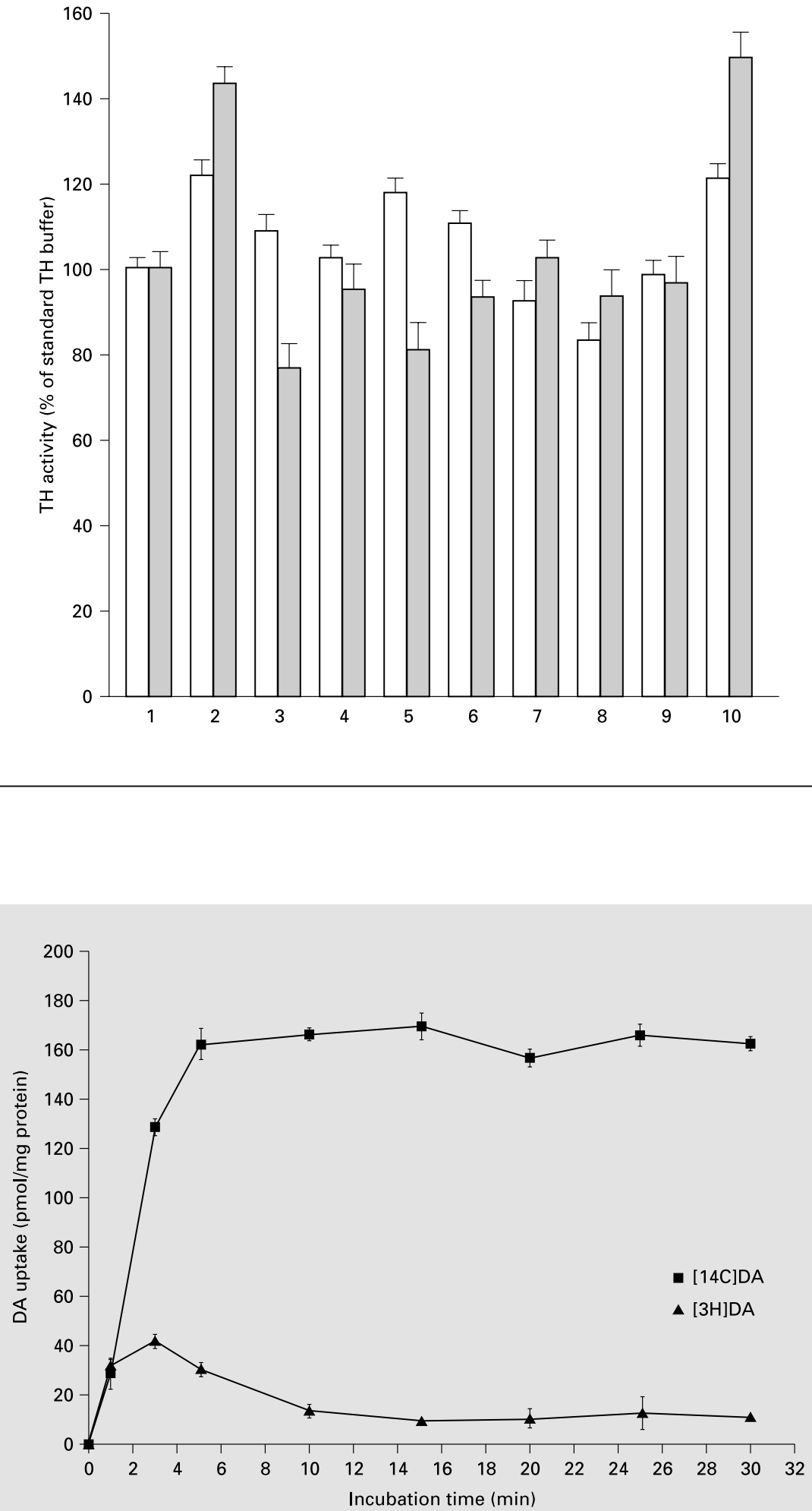
Fig. 6. Separation of tyrosine and DA on an anion exchange column. a Elution pattern of standard tyrosine $(45,000 \mathrm{dpm})$ and dopamine $(15,000 \mathrm{dpm})$ on an anion exchange column. Tyrosine was eluted out when washed with $\mathrm{H}_{2} \mathrm{O}$ (first peak), while DA was eluted later with $80 \mathrm{mM} \mathrm{HCl}$ as indicated in the second peak. b Elution pattern of the content extracted from synaptic vesicles as described in 'Materials and Methods'. The first peak corresponding to tyrosine is the nonspecifically absorbed tyrosine, the second large peak corresponding to the standard DA is newly synthesized $\left[{ }^{14} \mathrm{C}\right] \mathrm{DA}$ taken up by DA synaptic vesicles. The small peak at the same position as $\left[{ }^{14} \mathrm{C}\right] \mathrm{DA}$ is $\left[{ }^{3} \mathrm{H}\right] \mathrm{DA}$ taken up from the pre-existing [ $\left.{ }^{3} \mathrm{H}\right] \mathrm{DA}$ pool.
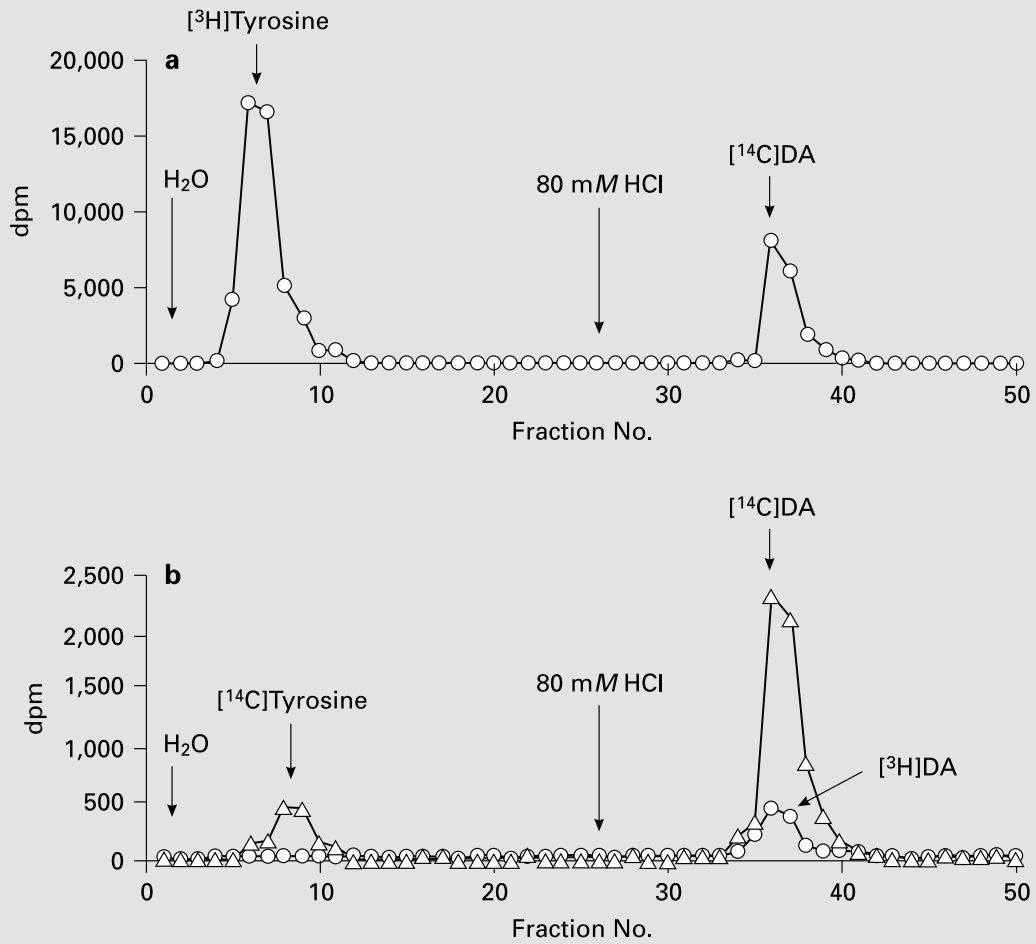

newly synthesized $\left[{ }^{14} \mathrm{C}\right] \mathrm{DA}$, but not the pre-existing $\left[{ }^{3} \mathrm{H}\right] \mathrm{DA}$, was preferentially taken up by vesicular DA transporter and reached saturation to about $160 \mathrm{pmol} / \mathrm{mg}$ protein, whereas the uptake of pre-existing $\left[{ }^{3} \mathrm{H}\right] \mathrm{DA}$ was only about $400 \mathrm{pmol} / \mathrm{mg} /$ protein.

\section{Identification of Uptake Contents as Newly \\ Synthesized DA from Tyrosine}

The majority of ${ }^{14} \mathrm{C}$-labeled content transported into the SVs was identified as DA (fig. 6b) since it has the same elution pattern as standard DA, as shown in figure $6 \mathrm{a}$. The small amount of $\left[{ }^{14} \mathrm{C}\right]$ tyrosine in the synaptic vesicle was probably due to the contamination of remaining $\left[{ }^{14} \mathrm{C}\right] \mathrm{ty}-$ rosine on the filter paper. The small portion of $\left[{ }^{3} \mathrm{H}\right] \mathrm{DA}$ detected in the synaptic vesicles likely resulted from the initial uptake by vesicular monoamine transporter when the amount of newly synthesized DA was low. These results suggest that the content taken up by dopaminergic synaptic vesicles was not the substrate, $\left[{ }^{14} \mathrm{C}\right]$ tyrosine, but newly synthesized $\left[{ }^{14} \mathrm{C}\right] \mathrm{DA}$ from $\left[{ }^{14} \mathrm{C}\right]$ tyrosine by synaptic vesicle-associated $\mathrm{TH}$ and $\mathrm{AADC}$.

\section{Discussion}

Two methods are commonly used for assaying $\mathrm{TH}$ activity. The first is based on the release of $\left[{ }^{3} \mathrm{H}\right] \mathrm{H}_{2} \mathrm{O}$ from $\left[{ }^{3} \mathrm{H}\right]$ tyrosine catalyzed by $\mathrm{TH}$. The second is a coupling assay based on the TH-catalyzed conversion of $L-1-{ }^{14} \mathrm{C}$ tyrosine to $L-1-{ }^{14} \mathrm{C}$-Dopa, followed by decarboxylation of $\left[{ }^{14} \mathrm{C}\right]$ DOPA by AADC. However, most studies of TH reported in the literature were conducted using the coupled methods. This coupled hydroxylation-decarboxylation method is only useful if the conditions tested only affect TH but not decarboxylase. Studies on the relationship between phosphorylation of AADC and its activation are less well investigated than that of TH. Only a few reports demonstrate that the AADC activity increases when it is phosphorylated by PKA [4] or PKC [20] in vivo. However, a lack of regulation of the AADC by PKA or PKC in vitro has also been reported [21]. In the present study, we used the method measuring the $\mathrm{TH}$ activity directly to avoid the complication of the coupled methods as mentioned above.

Although TH has been extensively studied, most studies have been done only with STH, but not MTH. Here, 


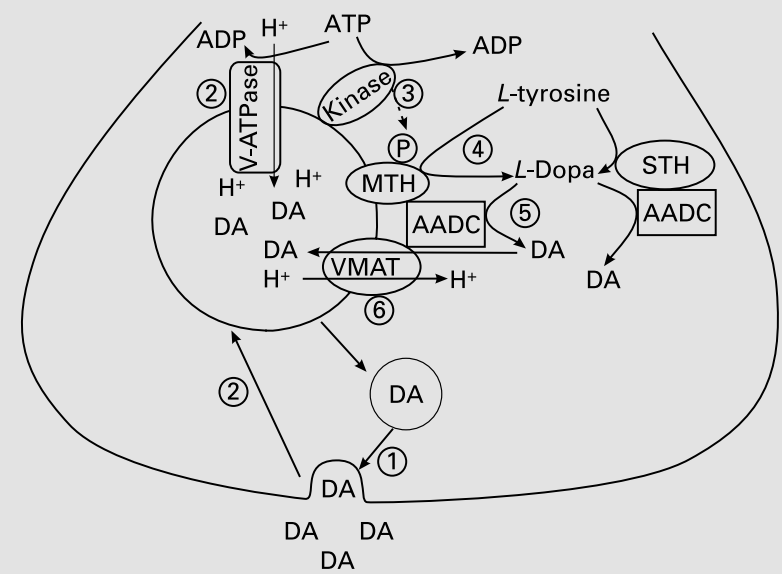

Fig. 7. A proposed model linking neuronal stimulation to activation of $\mathrm{TH}$ and a functional coupling between dopamine synthesis and packaging into synaptic vesicles.

we report that both MTH and STH are activated by ATP and inactivated by CIP, suggesting that $\mathrm{TH}$ is regulated by protein phosphorylation. Although MTH is similar to STH in that both forms of TH are activated by phosphorylation and inhibited by dephosphorylation, there is one major difference between MTH and STH, namely, activation of MTH but not STH by ATP appears to be mediated by the proton gradient which is maintained by V-type ATPase. This notion is supported by the observations that ATP activation of MTH was abolished under conditions that disrupt the proton gradient of synaptic vesicles, such as in the presence of CCCP, gramicidin, and bafilomycin A1.

In regard to the nature of $\mathrm{TH}$ phosphorylation and its effect on TH activity, there is a consensus that phosphorylation of $\mathrm{Ser}^{40}$ increases TH activity [7]. Phosphorylation of $\operatorname{Ser}^{19}$ has also been reported to increase TH activity in the presence of an activator, $\mathrm{Ca}^{2+}$. However, phosphorylation of $\mathrm{Ser}^{31}$ appears to have no effect on STH activity. Thus, STH is regulated by multiple kinases. In the present study, we have shown that MTH, like STH, is likely to be regulated by multiple kinases such as PKA and CaMKII since the activators of these kinases, e.g., cAMP and $\mathrm{Ca}^{2+}$, activated both forms of $\mathrm{TH}$ activity. However, further studies are needed to elucidate the relationship between phosphorylation and $\mathrm{TH}$ activity.

The newly synthesized DA from tyrosine was preferentially taken up by VMAT-2 over the pre-existing DA pool, suggesting that synaptic vesicle MTH is responsible for
DA synthesis and transport into synaptic vesicles. It is reasonable to speculate, based on the uptake data, that AADC, the second enzyme involved in DA synthesis, is also possibly synaptic vesicle-associated. Whether there is a protein complex of MTH and AADC associated with synaptic vesicle warrants further investigation.

Recently, we have shown that the synthesis of GABA in mammalian CNS is regulated through proton gradientdependent protein phosphorylation [10]. We further reported that there is a functional and structural coupling between GABA synthesis and GABA packaging into synaptic vesicles $[10,12]$. Here we report similar findings for the DA system. We have shown that the synthesis of DA by $\mathrm{TH}$ is also regulated by protein phosphorylation which is dependent upon the proton gradient of synaptic vesicles. Therefore, we propose that a general mechanism linking the neuronal stimulation to the enhanced neurotransmitter synthesis and transport into synaptic vesicles is present in the GABAergic as well as the dopaminergic systems, as illustrated below (fig. 7). When neurons are under depolarizing conditions, $\mathrm{Ca}^{2+}$ ions enter the nerve terminal through voltage gated-calcium channels, resulting in vesicular release of dopamine by a kiss and run mechanism [6] or exocytosis (step 1). The proton gradient is then restored on synaptic vesicles through V-type ATPase activity (step 2). MTH is then activated by proton gradient-dependent protein phosphorylation mediated by synaptic vesicle-associated protein kinase, which is activated by influx of $\mathrm{Ca}^{2+}$ from step 1 (step 3). $L$-Tyrosine is converted to $L$-Dopa (step 4). Another DA synthesizing enzyme, AADC, has been shown to be phosphorylated and activated in the presence of PKA [4] and PKC activator [21]. Hence, AADC is likely to be activated also by proton gradient-dependent protein phosphorylation by synaptic vesicle-associated protein kinases (step 5). Therefore, more DA is generated due to increased activity of both TH and AADC. Newly synthesized DA is then transported into synaptic vesicles by vesicular monoamine transporter (VMAT) (step 6). These refilled vesicles are ready to release DA upon arrival of another action potential. Furthermore, the influx of $\mathrm{Ca}^{2+}$ into synaptic vesicles also activates the $\mathrm{Ca}^{2+}$-dependent protein kinase (e.g. CaMKII), resulting in phosphorylation and activation of STH. The newly synthesized DA by STH can also be transported to the synaptic vesicles by VMAT, although at a much slower rate, to provide basal activity.

The model proposed here for the DA system differs from the one we previously proposed for the GABAergic system in that there are two enzymes involved in the synthesis of DA, namely, TH and AADC, whereas there is 
only one enzyme, namely, GAD, involved in GABA synthesis. Hence, for the DA model, we propose a structural coupling between vesicular DA transporter and both $\mathrm{TH}$ and AADC, while for the GABA model, vesicular GABA transporter is coupled to GAD only.

In summary, $\mathrm{TH}$ is regulated presumably at multiple sites by different protein kinases for both the soluble and membrane-bound forms. In addition, ATP activation of MTH is dependent on the integrity of the proton gradient of synaptic vesicles. Furthermore, the model we proposed recently for the GABAergic system showing functional and structural coupling between neurotransmitter synthe- sis and its packaging into synaptic vesicles appears to be a general mechanism applicable to the DA system. The nature of molecular anchoring of MTH to synaptic vesicles and coupling to the vesicular dopamine transporter requires further investigation.

\section{Acknowledgment}

This work was supported in part by NIH (NS37851) (J.-Y.W.), MH (43429) (S.C.F.) and the Charles E. Schmidt Family Foundation (J.-Y.W.). The assistance from Di Sha and Heng Wu is appreciated.

\section{References}

1 Albin RL, Reiner A, Anderson KD, Penney JB, Young AB. Striatal and nigral neuron subpopulations in rigid Huntington's disease: Implications for the functional anatomy of chorea and rigidity-akinesia. Ann Neurol 27:357-365; 1990.

2 Bao J, Cheung WY, Wu JY. Brain $L$-glutamate decarboxylase. Inhibition by phosphorylation and activation by dephosphorylation. J Biol Chem 270:6464-6467;1995.

3 Cambell DG, Hardie DG, Viullet RP. Identification of four phosphorylation sites in the Nterminal region of tyrosine hydroxylase. J Biol Chem 261:10489-10492;1986.

4 Duchemin AM, Berry MD, Neff NH, Hadjiconstantinou M. Phosphorylation and activation of brain aromatic $L$-amino acid decarboxylase by cyclic AMP-dependent protein kinase. J Neurochem 75:725-731;2000.

5 Floor E, Leventhal PS, Wang Y, Meng L, Chen W. Dynamic storage of dopamine in rat brain synaptic vesicles in vitro. $\mathrm{J}$ Neurochem 64 : 689-699;1995.

6 Gandhi SP, Stevens CF. Three modes of synaptic vesicular recycling revealed by single-vesicle imaging. Nature 423:607-613; 2003.

7 Havvik J, Schelling DL, Campbell DG, Andersson KK, Glatmark T, Cohen P. Identification of protein phosphatase $2 \mathrm{~A}$ as the major tyrosine hydroxylase phosphatase in adrenal medulla and corpus striatum: evidence from the effects of okadaic acid. FEBS Lett 251:36$42 ; 1989$.
8 Haycock JW, Ahn NG, Cobb MH, Krebs EG. ERK1 and ERK2, two microtubule-associated protein kinases, mediate the phosphorylation of tyrosine hydroxylase at serine 31 in situ. Proc Natl Acad Sci USA 89:2365-2369;1992.

9 Haycock JW, Haycock DA. Tyrosine hydroxylase in rat brain dopaminergic nerve terminals: Multiple-site phosphorylation in vivo and in synaptosomes. J Biol Chem 266:5650-5657; 1991.

10 Hsu C, Thomas C, Chen W, Davis KM, Foos T, Chen JL, Wu E, Floor E, Schloss V, Wu JY. Role of synaptic vesicle proton gradient and protein phosphorylation on ATP-mediated activation of membrane-associated brain glutamate decarboxylase. J Biol Chem 274:2436624371;1999.

11 Ichinose $\mathrm{H}$, Boye $\mathrm{T}$, Fujita $\mathrm{K}$, Pantucek F, Lange K, Riederer P, Nagatsu T. Quantification of mRNA of tyrosine hydroxylase and aromatic $L$-amino acid decarboxylase in the substantia nigra in Parkinson's disease and schizophrenia. J Neural Transm 8:149-158;1994.

12 Jin H, Wu H, Osterhaus G, Wei J, Davis K, Sha D, Floor E, Hsu C, Kopke R, Wu JY. Demonstration of functional coupling between $\gamma$-aminobutyric acid (GABA) synthesis and vesicular GABA transport into synaptic vesicles. Proc Natl Acad Sci USA 100:4293-4298;2003.

13 Kuczenski RT, Mandell AJ. Regulatory properties of soluble and particulate rat brain tyrosine hydroxylase. J Biol Chem 247:3114-3122; 1972.
14 McGeer EG, Gibson S, McGeer PL. Distribution of tyrosine hydroxylase in human and animal brain. J Neurochem 18:1647-1658;1971.

15 Reinhard JF, Smith GK, Nichol CA. A rapid and sensitive assay for tyrosine-3-monooxygenase based upon release of ${ }^{3} \mathrm{H}_{2} \mathrm{O}$ and absorption of $\left[{ }^{3} \mathrm{H}\right]$-tyrosine by charcoal. Life Sci 39:21852189;1986.

16 Shibuya H, Watanabe S, Toru M. Separation of homovanillic acid and vanillylmandelic acid with ion-exchange resin column. Experientia 31:622-623;1975.

17 Tang X, Hsu C, Schloss JV, Faiman MD, Wu E, Yang C, Wu JY. Protein phosphorylation and taurine biosynthesis in vivo and in vitro. $\mathrm{J}$ Neurosci 17:6947-6951;1997.

18 Vulliet PR, Hall FL, Mitchell JP, Hardie DG. Identification of a novel proline-directed serine/threonine protein kinase in rat pheochromocytoma. J Biol Biochem 264:16292-16298; 1989.

19 Waters CM, Peck R, Rossor M, Reynolds GP, Hunt SP. Immunocytochemical studies on the basal ganglia and substantia nigra in Parkinson's disease and Huntington's disease. Neuroscience 25:419-438;1988.

20 Waymire JC, Haycock JW. Lack of regulation of aromatic $L$-amino acid decarboxylase in intact bovine chromaffin cells. J Neurochem 81 : 589-593;2002.

21 Young EA, Neff NH, Hadjiconstantinou M. Phorbol ester administration transiently increases aromatic $L$-amino acid decarboxylase activity of the mouse striatum and midbrain. $\mathrm{J}$ Neurochem 63:694-697;1994. 
Copyright: S. Karger AG, Basel 2003. Reproduced with the permission of S. Karger AG, Basel. Further reproduction or distribution (electronic or otherwise) is prohibited without permission from the copyright holder. 
BioMed Central publishes under the Creative Commons Attribution License (CCAL). Under the CCAL, authors retain copyright to the article but users are allowed to download, reprint, distribute and /or copy articles in BioMed Central journals, as long as the original work is properly cited. 